\title{
Aminolysis of poly(ethylene terephthalate) waste bottle with tetra/hexamethylene diamine and characterization of alpha, ohmega-diamine products
}

- Hoang Ngoc Cuong

- Dang Hoang Yen

University of Science, VNU-HCM

(Received on $21^{\text {th }}$ November 2016, accepted on $18^{\text {th }}$ July 2017)

ABSTRACT

The aminolysis of poly(ethylene terephthalate) (PET) waste bottle with excess amount of aliphatic diamines, such as tetramethylenediamine (TMDA) and hexamethylenediamine (HMDA) without catalyst has been carried out. Each trimers and pentamers in the obtained products were isolated and characterized by FTIR, NMR, HPLC methods. Although an excess of diamine was employed, longer blocks of oligomers were still formed as minor products.

Keywords: bis(4-aminobutyl) terephthalamide (BABT), bis(6-aminohexyl) terephthalamide (BAHT), hexamethylenediamine (HMDA), oligomers, poly(ethylene terephthalate) (PET), tetramethylenediamine (TMDA), poly(hexamethylene terephthalamide), poly(tetramethylene terephthalamide), waste bottle recycling

\section{INTRODUCTION}

Poly(ethylene terephthalate) (PET) finds applications across diverse industries such as food and beverage packaging, automotive, electronics among the others. Every year, hundreds billion PET bottles are produced worldwide. The increasing demand of PET has resulted in the increasing waste. Stringent environmental rules and regulations by government requires to recycle PET waste. A large quantity of PET waste is recycled by a physical process and just a smaller one by chemical method. Chemical recycling is defined as the process leading to complete or partial degradation of waste polymer to monomer or oligomer, respectively. Chemical recycling of PET does not only serve as a method to reduce the solid waste, to conserve raw petrochemical products and energy, but also contributes to the manufacturing value-added products.

Based on the ester functionality, PET may react with water, alcohols, amines to produce monomer/oligomers. From these small molecules unsaturated polyester, polyurethane, etc. were prepared [1].

Ester group in PET can be converted into stable amide by the reaction with amine. From this functional group transformation, PET was modified or degraded by reaction with various amines. For instance, PET fiber surface was modified by using 3-aminopropyltriethoxysilane $[2,3], n$-butylamine vapor and aqueous $n$ butylamine [4], $n$-propylamine and methylamine [5], by diamines [6] or by multifunctional amines [7]. The aminolytic depolymerization of PET with ethanolamine has been investigated under reflux in the presence of glacial acetic acid, 
sodium acetate and potassium sulphate, as catalysts [8], or under microwave energy and using catalysts [9], or under microwave irradiation and without the use of any catalyst [10].

According to Fukushima $\mathrm{K}$ et al [11], the degradation of PET was carried out in various amines, such as primary amines (aliphatic, aromatic, click functionalized, tertiary functionalized) and diamines, using the organocatalyst 1,5,7-triazabicyclo[4.4.0]dec-5ene (TBD). Structures of the obtained terephthalamides were confirmed by ${ }^{1} \mathrm{H}$ - and ${ }^{13} \mathrm{C}$ $\mathrm{NMR}$, and their melting points were determined by DSC.

The terephthalamide oligomeric products are prepared not only by the degradation of PET, but also by the aminolysis of terephthalate monomers. The synthesis of bis(6aminohexyl)terephthalamide (BAHT or trimer 6T6-diamine) was derived from the synthesis of bis(4-aminobutyl)terephthalamide (BABT or trimer 4T4-diamine) [12]. BABT was prepared by the reaction of dimethyl terephthalate (DMT) with tetramethylendiamine (molar ratio 1:3). The product structure was confirmed just by FTIR method. Krijgsman et al [13] also disclosed the preparation of $\quad$ bis $(\omega$-aminoalkyl) terephthalamides from DMT and $\alpha, \omega$ bisaminealkanes. The alkanes were used as ethane, propane, butane, hexane, heptane and octane. The authors have used $n$-butyl acetate to recrystallize the crude products, however the yield of this process was as low as $48 \%$. The formation of higher oligomers, such as pentamer 6T6T6-diamine and heptamer 6T6T6T6-diamine, was also proposed. In another paper, the overall yield of BAHT was reported by Martijn van der Schuur [14] with only $16 \%$.

Polyterephthalamide such as poly (hexamethylene terephthalamide) (PA6T) is known for their thermal stability, chemical resistance, high strength, and high modulus as fibers [15].

In the previous paper [16] we described the aminolysis of PET with ethylenediamine (EDA). The trimeric and pentamer products were isolated and identified by FTIR, NMR, HPLC-MS, DSC, TGA. In this research work, the longer chain aliphatic diamines, namely tetramethylendiamine (TMDA) and hexamethylenediamine (HMDA) were used for the aminolysis reaction of PET, using a modified procedure to improve the conversion. By using excess of diamine, the oligomeric products have amine end groups and can be used to prepare high performance polymers such as polyamide, polyimide, polymaleimide, etc.

\section{MATERIALS AND METHODS}

\section{Materials}

Tetramethylenediamine (TMDA) and hexamethylenediamine (HMDA) were obtained from Sigma Aldrich. Acetone, methanol were from Chemsol-VN. PET waste colorless bottle was washed with water and then cut into $3 \mathrm{~mm} \mathrm{x}$ $4 \mathrm{~mm}$ flakes and dried in an oven for 3 days at 80 ${ }^{\circ} \mathrm{C}$.

\section{Characterization methods}

An FTIR-TENSOR II Bruker spectrometer was used in the transmission mode to record spectra from $\mathrm{KBr}$ pellets. ${ }^{1} \mathrm{H}-\mathrm{NMR}$ and ${ }^{13} \mathrm{C}-\mathrm{NMR}$ spectra were recorded with a Bruker ARX-500 NMR Spectrometer operating at $500 \mathrm{MHz}\left({ }^{1} \mathrm{H}\right)$ and $125 \mathrm{MHz}\left({ }^{13} \mathrm{C}\right)$ in $d_{4}$-acetic acid solution.

The analysis conditions of the HPLC-ESIMS (1200 Series micrOTOF - QII Bruker, Agilent Technologies, Palo Alto, CA, USA) were as follows. Column: ACE 3-C18 $(150 \times 4.6 \mathrm{~mm}$ i.d., $3 \mu \mathrm{m}$ particle size) (Agilent Technologies, USA) reverse phase columns. HPLC conditions: injection volume of $10 \mu \mathrm{L}$, column temperature of $25{ }^{\circ} \mathrm{C}$ and flow rate of $0.4 \mathrm{~mL} \mathrm{~min}^{-1}$. The mobile phases were used for A solution (water 
containing $0.1 \%$ formic acid) and for B solution (methanol containing $0.1 \%$ formic acid). Linear gradients for the B solution were programmed from $10 \%$ to $100 \%$ in $20 \mathrm{~min}$, hold $100 \%$ for 5 min. UV detection wavelength: $242 \mathrm{~nm}$. The HPLC instrument was connected to a Bruker Daltonics MicrOTOF QII time-of-flight mass spectrometer, equipped with an orthogonal ESI source and a 6-port divert valve. The MS instrument was operated in positive ion mode using a range of $50-3000 \mathrm{~m} / \mathrm{z}$. External calibration was performed prior to each run using cluster ions from an Agilent tune mix solution. The solution for HPLC analysis was prepared by dissolving about $4 \mathrm{mg}$ solid materials in $50 \mathrm{~mL}$ of formic acid.

\section{Reaction of PET with TMDA, HMDA}

A mixture of $3.00 \mathrm{~g}(15.6 \mathrm{mmol})$ of PET flake and a specific mass of diamines TMDA or HMDA was heated in a $100 \mathrm{~mL}$ round bottom flask at $80{ }^{\circ} \mathrm{C}$. After heating for $1 \mathrm{~h}$, the reaction mixture became thick and it was diluted with $5.0 \mathrm{~mL}$ of methanol. This solvent treatment was repeated every hour until overall $30 \mathrm{~mL}$ of methanol was added. The reaction mixture was continued heating for an additional $14 \mathrm{~h}$ and then allowed to cool to room temperature and filtered. The insoluble material, labelled as part A, was rinsed carefully with methanol and acetone, dried at $60{ }^{\circ} \mathrm{C}$ for $24 \mathrm{~h}$ in a vacuum oven, and its mass was recorded. The volatile materials in the combined filtrate and rinsed solvents were removed by a rotary evaporator. The white precipitate was filtered, rinsed carefully with cool methanol, acetone, dried at $60{ }^{\circ} \mathrm{C}$ for $24 \mathrm{~h}$ in a vacuum oven, and then its mass was recorded and labelled as part B. Part A and B solid materials were subjected to FTIR, NMR, HPLC-MS analysis.

\section{RESULTS AND DISCUSSION}

The general aminolysis reaction of PET with tetramethylenediamine (TMDA) or hexamethylenediamine (HMDA) was shown in Scheme 1.

Reactant diamines were used in excess, therefore amine groups would caped at both ends of an oligomeric chain. A trimer is assumed to be formed from one molecule of terephthalic acid and two molecules of diamine. A pentamer is formed from two molecules of terephthalic acid and three molecules of diamine.

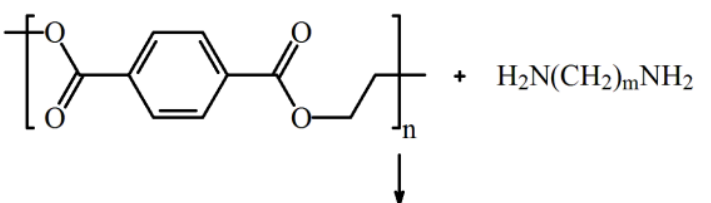

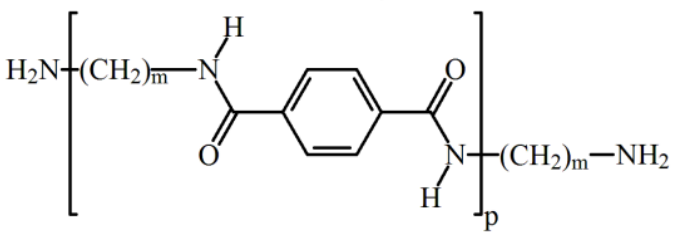

Scheme 1. Aminolysis reaction of PET with tetramethylenediamine $(\mathrm{m}=4)$ or hexamethylenediamine $(\mathrm{m}=6)$ and formation of trimer $(\mathrm{p}=1)$ or pentamer $(\mathrm{p}=2)$.

Table 1. Values of $\mathrm{m}, \mathrm{p}$ and names of PET aminolysis products corresponding to the chemical structure shown in Scheme 1

\begin{tabular}{|c|c|l|c|c|}
\hline $\mathrm{m}$ & $\mathrm{p}$ & Names & Abbreviations & Part \\
\hline \multirow{2}{*}{4} & 1 & Bis(4-aminobutyl)terephthalamide & BABT & $\mathrm{B}$ \\
\cline { 2 - 5 } & $\geq 2$ & $\alpha, \omega$-Bisaminoligo(tetramethylene terephthalamide) & AOBT & $\mathrm{A}$ \\
\hline \multirow{2}{*}{6} & 1 & Bis(6-aminohexyl)terephthalamide & BAHT & $\mathrm{B}$ \\
\cline { 2 - 5 } & $\geq 2$ & $\alpha, \omega$-Bisaminoligo(hexamethylene terephthalamide) & AOHT & A \\
\hline
\end{tabular}




\section{Aminolysis of PET with tetramethylenediamine (TMDA)}

The reaction of PET flake with excess TMDA produces oligomers. We started from the input molar ratio of TMDA:PET = 8:1. By using solvent methanol treatment of the reaction mixture, two parts were separated, with $\mathrm{A}$ is a methanol insoluble part and $\mathrm{B}$ is a methanol soluble part. Part B contains mainly a lower molecular weight trimer bis(4-aminobutyl) terephthalamide (BABT). Part A consists largely of higher molecular weight pentamer of $\alpha, \omega$ aminoligo(tetramethylene terephthalamide) (AOBT). The identifications and characterizations of part B and part A are described in detail as follows.

The aminolysis of ester groups in PET structure by an aliphalic diamine can be confirmed by observing the disappearance of PET flake in the reaction mixture and by FTIR analysis (Fig. 1). The conversion of terephthalate ester to terephthalamide group was evidenced by the shifting of $\mathrm{C}=\mathrm{O}$ stretching band at $1715 \mathrm{~cm}^{-1}$ of ester to $1623 \mathrm{~cm}^{-1}$ of amide, the appearance of secondary amide $\mathrm{N}-\mathrm{H}$ stretching band at $3300 \mathrm{~cm}^{-1}$ and amide II band at $1544 \mathrm{~cm}^{-1}$. The $\mathrm{N}-\mathrm{H}$ stretching band of primary amine end groups could only be seen in the part B- BABT spectrum at $3342 \mathrm{~cm}^{-1}$. However, for the pentamer, due to small contribution of the amine end groups to a much higher molecular weight, this band for the amine end groups could not be detected. Four methylene groups $\left(\mathrm{CH}_{2}\right)_{4}$ show an asymmetric stretching at $2951 \mathrm{~cm}^{-1}$ and a symmetric stretching at $2871 \mathrm{~cm}^{-1}$. A band at 859 $\mathrm{cm}^{-1}$ is due to $\mathrm{C}$ (arom)-H out-of-plane hydrogen deformations for para substituted benzene.

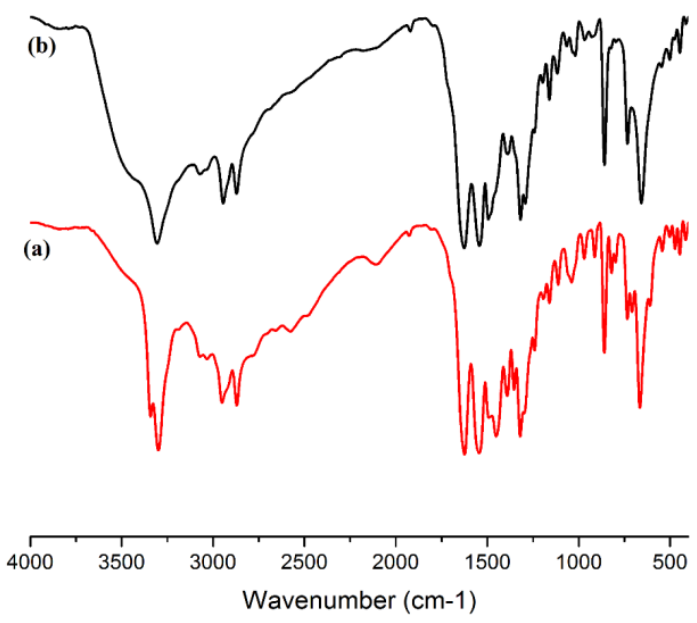

Fig. 1. FTIR spectra of (a) part B-BABT and (b) part A-AOBT obtained from the PET-TMDA reaction

Chemical structures of part B- BABT and part A- AOBT from PET-TMDA reaction were also confirmed by NMR spectroscopy (Fig. 2, 3).

The peaks observed in the ${ }^{1} \mathrm{H}-\mathrm{NMR}$ spectrum of part B- BABT (Fig. 2A) are attributed as follows: the single peak at $7.95 \mathrm{ppm}(4 \mathrm{H})$ is typical for symmetrical para-substituted aromatic protons, the two sets of triplet peaks at $3.509 \mathrm{ppm}$

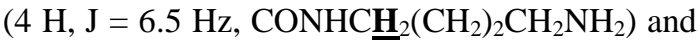
3.127 ppm $\left(4 \mathrm{H}, \mathrm{J}=7.5 \mathrm{~Hz}, \mathrm{CONHCH}_{2}\left(\mathrm{CH}_{2}\right)_{2}-\right.$ $\mathrm{CH}_{2} \mathrm{NH}_{2}$ ) are produced by the two sets of alpha methylene protons attached to amide and amine groups, respectively. The multiplet peaks at 1.82 and $1.76 \mathrm{ppm}$ are assigned to the beta methylene protons of amide/amine groups $(8 \mathrm{H}, \mathrm{m}$, $\left.\mathrm{CONHCH}_{2}\left(\mathrm{CH}_{2}\right)_{2} \mathrm{CH}_{2} \mathrm{NH}_{2}\right)$.

The ${ }^{13}$ C-NMR spectrum of part B- BABT (Fig 2B) shows typical resonances at $169.48 \mathrm{ppm}$ (2C, $\mathrm{C}=\mathrm{O}), 137.80$ ppm (2C, quart, aromatic $\mathrm{C}$ ), 128.60 ppm (4C, aromatic C-H), 40.66 ppm (2C, $\left.\mathrm{CONH} \underline{C H}_{2}\right), 40.28 \mathrm{ppm}\left(2 \mathrm{C}, \underline{\mathbf{C}} \mathrm{H}_{2} \mathrm{NH}_{2}\right), 26.84$, $25.36 \mathrm{ppm}\left(\mathrm{CH}_{2}\right)$. 

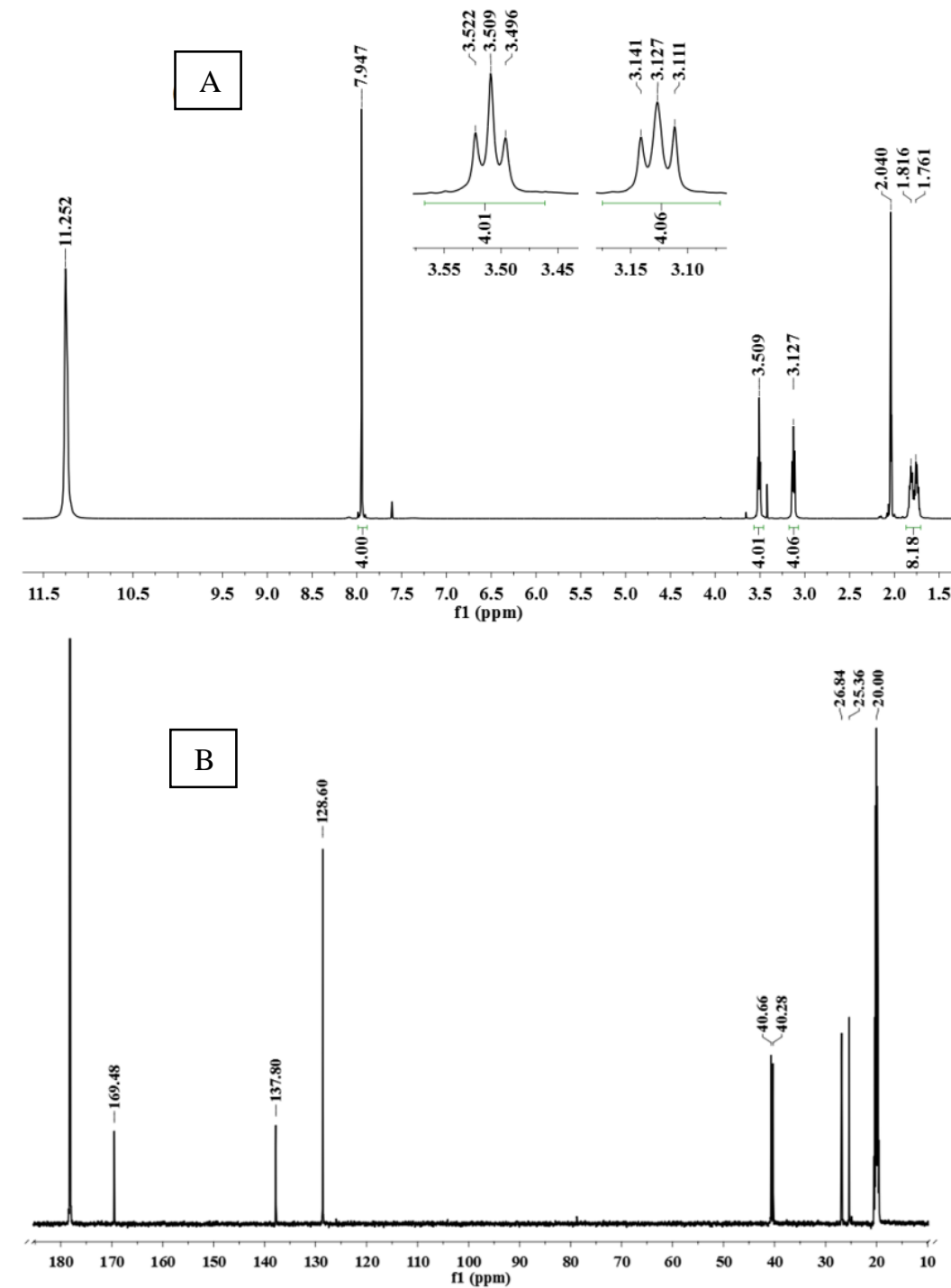

Fig. 2. (A) ${ }^{1} \mathrm{H}-\mathrm{NMR}$ and (B) ${ }^{13} \mathrm{C}-\mathrm{NMR}$ spectra in $\mathrm{CD}_{3} \mathrm{COOD}$ of part $\mathrm{B}-\mathrm{BABT}$ obtained from the PET-TMDA reaction

The peaks observed in the ${ }^{1} \mathrm{H}-\mathrm{NMR}$ spectrum of part A- AOBT (Fig. 3A) are attributed as follows: the singlet peak at $7.93 \mathrm{ppm}(8 \mathrm{H})$ is typical for aromatic-C-Hs, the singlet peak at $3.50 \mathrm{ppm}\left(8 \mathrm{H}, \mathrm{CONHC} \underline{\mathbf{H}}_{2}\right)$ and a triplet peak at $3.13 \mathrm{ppm}\left(4 \mathrm{H}, \quad \mathrm{J}=7.0 \mathrm{~Hz}, \quad \underline{\mathbf{H}}_{2} \mathrm{NH}_{2}\right)$ are produced by alpha methylene hydrogen atoms attached to the amide and amine groups, respectively. The single peaks at 1.75 and
$1.80 \mathrm{ppm}$ are assigned to the remaining methylene protons $(12 \mathrm{H})$.

The ${ }^{13} \mathrm{C}$-NMR spectrum of part A-AOBT (Fig. 3B) shows typical resonances at 169.48, 169.36 ppm (4C, C=O), 137.85, 137.68 ppm (4C, quart, aromatic C); 128.55 ppm (8C, aromatic C$\mathrm{H}), 40.82,40.65 \mathrm{ppm}$ (4C, $\left.\mathrm{CONH}_{\mathbf{C}}{ }_{2}\right)$,

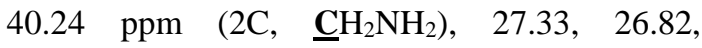
$25.34 \mathrm{ppm}\left(\mathrm{CH}_{2}\right)$. 


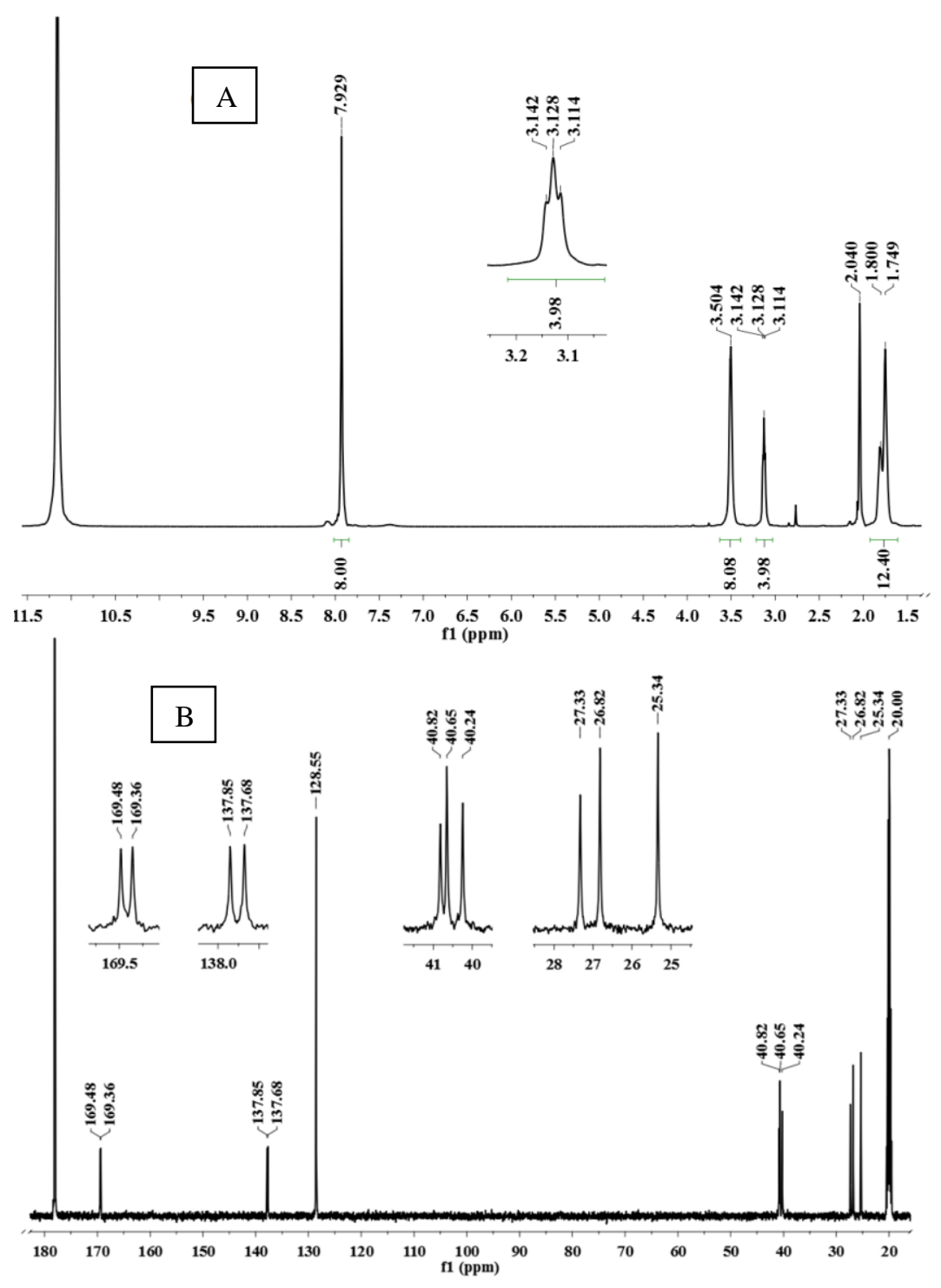

Fig. 3. (A) ${ }^{1} \mathrm{H}-\mathrm{NMR}$ and (B) ${ }^{13} \mathrm{C}-\mathrm{NMR}$ spectra in $\mathrm{CD}_{3} \mathrm{COOD}$ of part $\mathrm{A}-\mathrm{AOBT}$ obtained from the PET-TMDA reaction

The purity of the obtained products from the PET-TMDA reaction is determined by HPLCMS. Each part A- AOBT or part B-BABT is separated by HPLC and each peak in the chromatogram represents an individual compound that is further characterized by MS.

Chromatogram of part B- BABT (Fig 4A) shows a major peak at $3.0 \mathrm{~min}$ and a minor peak at $7.2 \mathrm{~min}$, corresponding to trimer BABT and pentamer AOBT respectively as confirmed by mass spectra. From the relative abundance of trimer and pentamer, then part B contains $94.3 \%$ trimer and $5.7 \%$ pentamer. This low content of pentamer cannot be detected by FTIR or NMR methods.

\section{Trang 106}



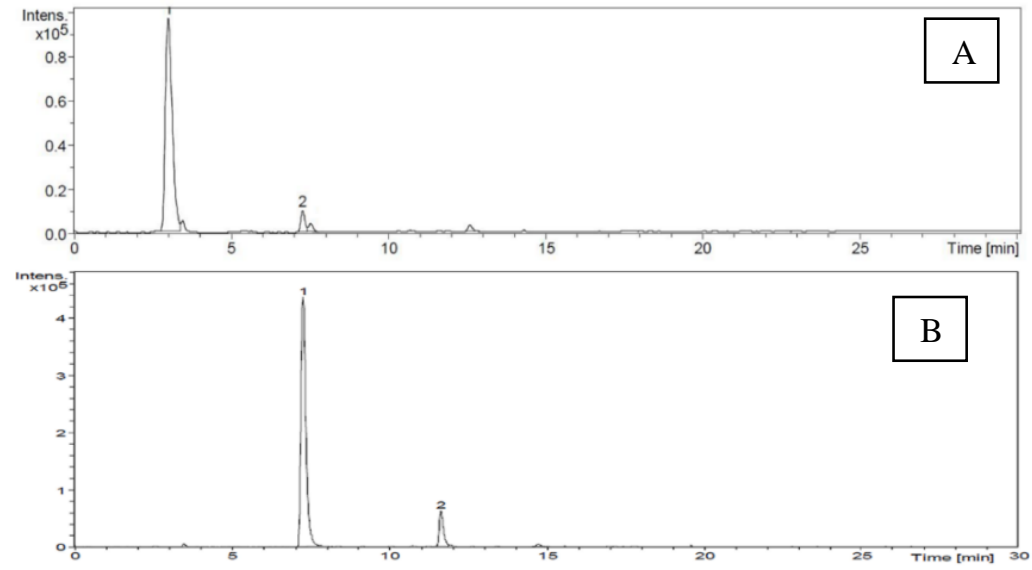

Fig. 4. HPLC chromatograms of (A) part B- BABT and (B) part A- BABT obtained from the PET-TMDA reaction

Chromatogram of part A- AOBT (Fig. 4B) shows a major peak at $7.2 \mathrm{~min}$ and a minor peak at $11.6 \mathrm{~min}$, corresponding to pentamer AOBT and heptamer respectively as identified by mass spectra. The relative abundance of pentamer and heptamer in HPLC chromatogram (Fig. 4B) showed that the part A- AOBT contains $90 \%$ pentamer and $10 \%$ heptamer.

Aminolysis of PET with hexamethylenediamine (HMDA)

By using the same experimental procedure and characterization methods as described above, the reaction of PET with HMDA has formed a methanol soluble part B containing mainly trimer bis(6-aminohexyl)terephthalamide (BAHT) and a methanol insoluble part A consisting of pentamer AOHT.
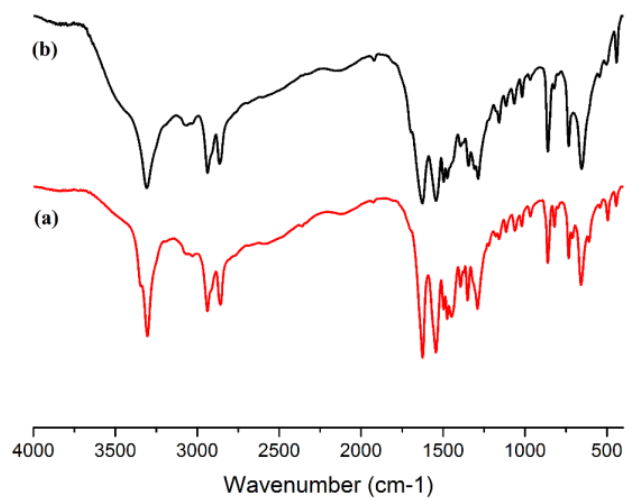

Fig. 5. FTIR spectra of (A) part B-BAHT and (B) part A-AOHT obtained from the PET-HMDA reaction
Two FTIR spectra (Fig. 5) show the same features of a secondary amide such as the stretching vibration of $\mathrm{C}=\mathrm{O}$ (amide-I band) at $1626 \mathrm{~cm}^{-1}$, and the N-H deformation at $1543 \mathrm{~cm}^{-1}$ (amide-II band). The minor difference can be seen as a weak peak at $3342 \mathrm{~cm}^{-1}$ of N-H stretching of the primary amine end group in BAHT.

The bands of six methylene chain of BAHT/AOHT at 2937, 2864 and $733 \mathrm{~cm}^{-1}$ become stronger compared with the FTIR spectra of BABT/AOBT (Fig. 1) having four methylene chain and BAET/AOET [16] having only two methylene chain. When the number of methylene chain increases the asymmetric stretching and symmetric stretching bands of $\mathrm{CH}_{2}$ shift to lower wave number or to lower energy. These findings are in fairly good agreement with the fact that the longer the methylene chain, the more flexible the vibration and then it required lower energy. Another band at $859 \mathrm{~cm}^{-1}$ is due to $\mathrm{C}($ arom)-H out-of-plane hydrogen deformations for para substituted benzene.

Part B- BAHT and part A- AOHT obtained from the PET-HMDA reaction were also characterized by NMR spectroscopy (Fig. 6, 7).

The peaks observed in the ${ }^{1} \mathrm{H}-\mathrm{NMR}$ spectrum of part B- BAHT (Fig. 6A) are attributed as follows: the single peak at $7.93 \mathrm{ppm}(4 \mathrm{H})$ is 
typical for symmetrical para-substituted aromatic ring, the two sets of triplet peaks at $3.47 \mathrm{ppm}(4 \mathrm{H}$, $\left.\mathbf{J}=7.0 \mathrm{~Hz}, \mathrm{CONHC}_{2}\left(\mathrm{CH}_{2}\right)_{4} \mathrm{CH}_{2} \mathrm{NH}_{2}\right)$ and $3.07 \mathrm{ppm}\left(4 \mathrm{H}, \mathrm{J}=7.5 \mathrm{~Hz}, \mathrm{CONHCH}_{2}\left(\mathrm{CH}_{2}\right)_{4^{-}}\right.$ $\underline{\mathrm{C}}_{2} \mathrm{NH}_{2}$ ) are produced by the two sets of alpha methylene hydrogen atoms attached to amide and amine groups correspondently. Two very closed peaks at 1,73 and $1.67 \mathrm{ppm}$ with a total of 8 hydrogens are methylene protons at beta positions of amine and amide groups. The single peak at $1.44 \mathrm{ppm}$ is attributed to gamma methylene protons of amino and amido groups.
The ${ }^{13} \mathrm{C}$-NMR spectrum of part B-BAHT (Fig 6b) shows typical resonances at $169.40 \mathrm{ppm}$ (2C, $\mathrm{C}=\mathrm{O}), 137.87$ ppm (2C, quart, aromatic C); 128.54 ppm (4C, aromatic C-H), 40.97ppm (2C, $\left.\underline{\mathrm{CH}}_{2} \mathrm{NH}_{2}\right), \quad 40.90$ ppm $\left(2 \mathrm{C}, \quad \mathrm{CONH}^{\mathrm{C}} \mathrm{H}_{2}\right)$, $29.71 \mathrm{ppm}\left(2 \mathrm{C}, \mathrm{CONHCH}_{2} \underline{\mathrm{CH}}_{2}\right), 27.88$ (2C, $\underline{\mathrm{CH}_{2}} \mathrm{CH}_{2} \mathrm{NH}_{2}$ ), and another methylene carbons appear at 27.05, $26.67 \mathrm{ppm}$.

The ${ }^{1} \mathrm{H}$ and ${ }^{13} \mathrm{C}$-NMR spectra have confirmed the structure of bis(6-aminohexyl) terephthalamide (BAHT).
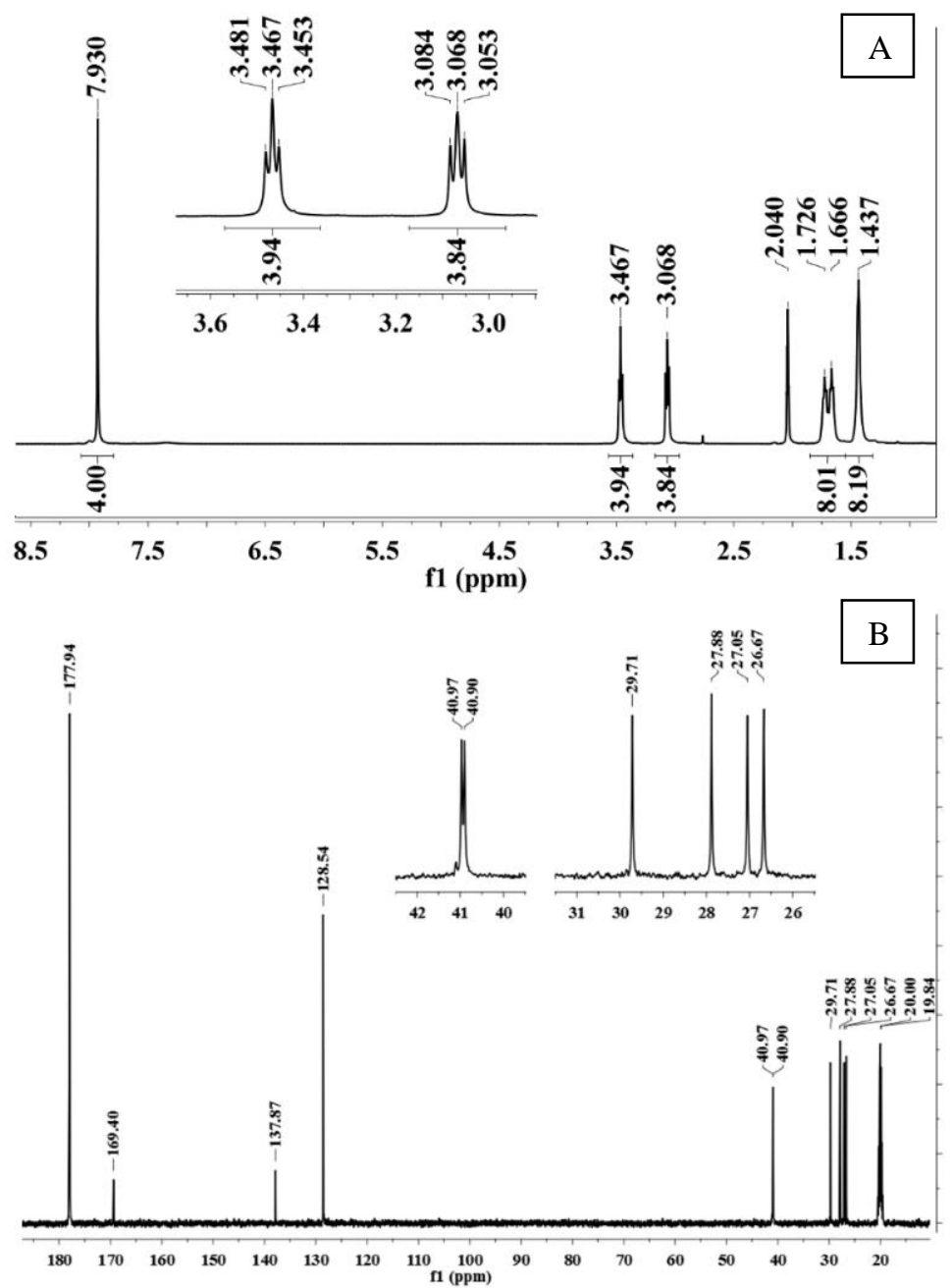

Fig. 6. (A) ${ }^{1} \mathrm{H}-\mathrm{NMR}$ and (B) ${ }^{13} \mathrm{C}-\mathrm{NMR}$ spectra in $\mathrm{CD}_{3} \mathrm{COOD}$ of part B-BAHT obtained from the PET-HMDA reaction

\section{Trang 108}


The peaks observed in the ${ }^{1} \mathrm{H}-\mathrm{NMR}$ spectrum of part A-AOHT (Fig. 7A) are attributed as follows: the single peak at $7.92 \mathrm{ppm}(8 \mathrm{H})$ is typical for aromatic protons of para-substituted aromatic ring, the two sets of triplet peaks at 3.47 $\operatorname{ppm}\left(4 \mathrm{H}, \mathrm{t}, \mathbf{J}=7.0 \mathrm{~Hz}, \mathrm{CONHC} \underline{\mathbf{H}}_{2}\right)$ and 3.06 ppm $\left(4 \mathrm{H}, \mathrm{t}, \mathrm{J}=7.5 \mathrm{~Hz}, \mathrm{RCH}_{2}\left(\mathrm{CH}_{2}\right)_{4} \mathrm{C}_{2} \mathrm{NH}_{2}\right)$ are produced by the two sets of alpha methylene hydrogen atoms attached to the amide and amine groups correspondently. Similar to the ${ }^{1} \mathrm{H}-\mathrm{NMR}$ of BAHT the beta and gamma methylene protons of amine/amide groups appear in 1.72, 1.66 and $1.44 \mathrm{ppm}$.

Table 2. Theoretical ratio of protons in $\alpha, \omega$-Bisaminoligo(hexamethylene terephthalamide)

\begin{tabular}{|c|c|c|c|c|c|c|}
\hline Oligomer & $\begin{array}{c}\text { Short } \\
\text { formula (*) }\end{array}$ & $\begin{array}{c}\text { Aromatic } \\
\text { protons }\end{array}$ & $\begin{array}{c}\text { Alpha } \\
\mathrm{C}_{2}-\mathrm{NH}_{2}\end{array}$ & $\begin{array}{c}\text { Alpha } \\
\mathrm{C}_{2}- \\
\mathrm{NHCO}\end{array}$ & $\begin{array}{c}\text { Beta } \mathrm{CH}_{2} \text { to } \\
\text { amine/amide }\end{array}$ & $\begin{array}{c}\text { Gamma } \mathrm{CH}_{2} \\
\text { to } \\
\text { amine/amide }\end{array}$ \\
\hline $\begin{array}{c}\text { Trimer } \\
\text { (BAHT) }\end{array}$ & $6 \mathrm{~T} 6$ & 4 & 4 & 4 & 8 & 8 \\
\hline Pentamer & 6T6T6 & 8 & 4 & 8 & 12 & 12 \\
\hline Heptamer & 6T6T6T6 & 12 & 4 & 12 & 16 & 16 \\
\hline
\end{tabular}

(*) T: terephthalamide: p-NHCOC $6 \mathrm{H}_{4} \mathrm{CONH}$; 6: hexamethylene: $\mathrm{NH}\left(\mathrm{CH}_{2}\right)_{6} \mathrm{NH}$.

Assuming that the mixture contains mainly $\mathrm{x}$ mol of pentamer and $(1-\mathrm{x})$ mol of heptamer. From the proton molar ratio at both ends or alpha to amine $\left(\mathrm{C}_{2} \mathrm{NH}_{2}\right)$ over aromatic protons of pentamer (4/8), heptamer (4/12) and our experimental data of AOHT (3.82/8) then $\mathrm{x}$ can be calculated based on ${ }^{1} \mathrm{H}-\mathrm{NMR}$ integral as $\mathrm{x}=$ 0.865 , or the part A contains $86.5 \% \mathrm{~mol}$ of pentamer and $13.5 \% \mathrm{~mol}$ of heptamer.

The ${ }^{13} \mathrm{C}-\mathrm{NMR}$ spectrum of part A-AOHT (Fig. 7B) shows typical resonances of pentamer of AOHT. In this pentamer structure, the aromatic ring becomes unsymmetrical then the carbonyl and C(ipso) are split into twin peaks at $169.42,169.39 \mathrm{ppm}(4 \mathrm{C}, \mathrm{C}=\mathrm{O})$, and 137.90, $137.80 \mathrm{ppm}$ (4C, quart, aromatic C), however 8 aromatic CHs appear as a singlet at $128.55 \mathrm{ppm}$. There are three peaks at $41.08,40.89 \mathrm{ppm}$ (4C, $\left.\mathrm{CONH}_{\mathbf{C}}{ }_{2}\right), 40.98 \mathrm{ppm}\left(2 \mathrm{C}, \underline{\mathbf{C}} \mathrm{H}_{2} \mathrm{NH}_{2}\right)$ are typical for alpha methylene carbons of amide/amine groups. There are two peaks at $29.83,29.73 \mathrm{ppm}$ are due to two types of beta methylene carbon to amide $\underline{\mathbf{C}} \mathrm{H}_{2} \mathrm{CH}_{2} \mathrm{NHCO}$ and only one type of beta of methylene carbon to amine $\underline{\mathbf{C}} \mathrm{H}_{2} \mathrm{CH}_{2} \mathrm{NH}_{2}$ at $27.89 \mathrm{ppm}$. Three other peaks at 27.27, 27.07 and $26.69 \mathrm{ppm}$ are attributed to gamma methylene carbons of amide/amine groups.

The structure of heptamer cannot be detected by ${ }^{13} \mathrm{C}$-NMR due to similarity with that of pentamer. 

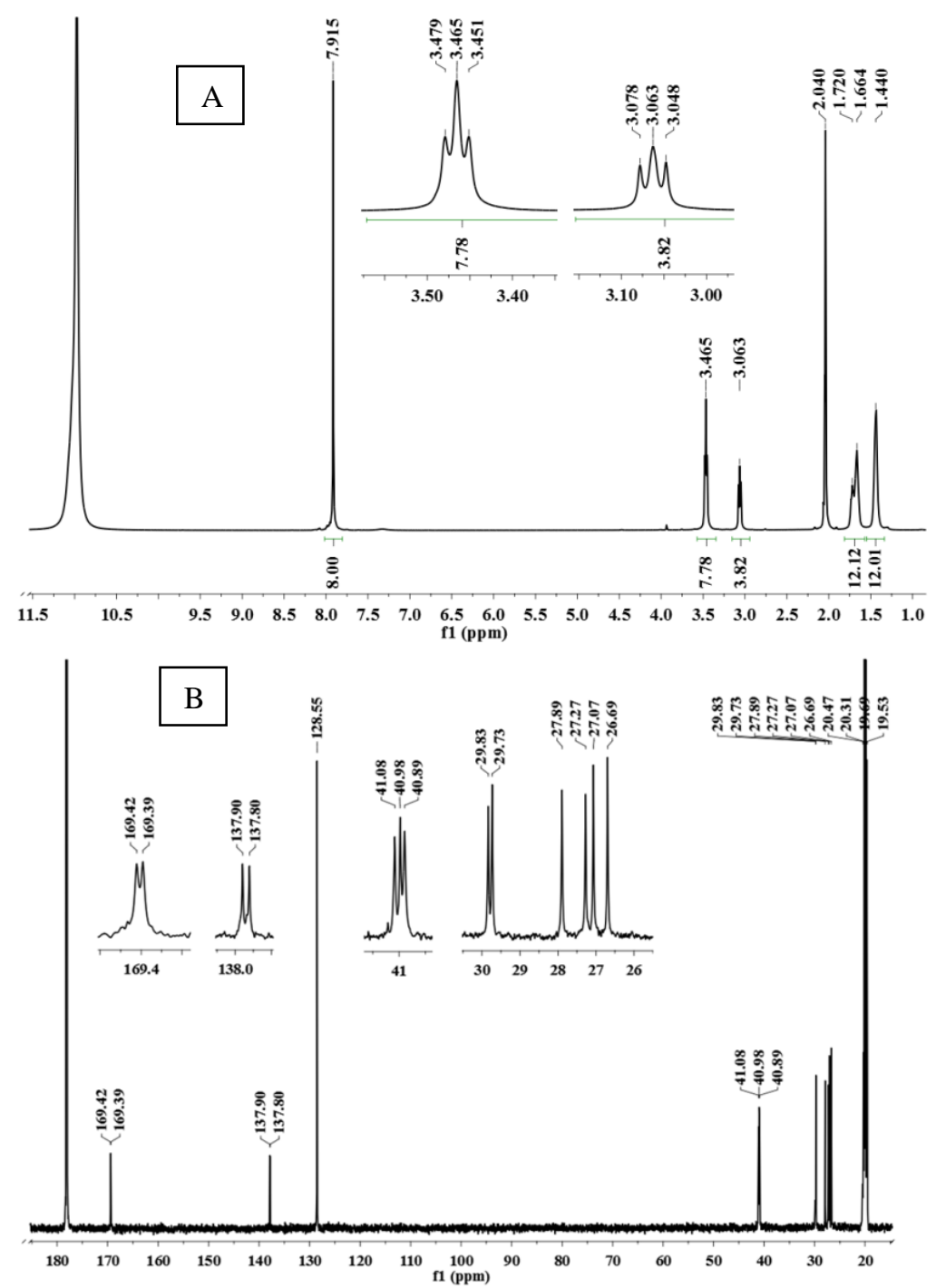

Fig. 7. (A) ${ }^{1} \mathrm{H}-\mathrm{NMR}$ and (B) ${ }^{13} \mathrm{C}-\mathrm{NMR}$ spectra in $\mathrm{CD}_{3} \mathrm{COOD}$ of part A-AOHT obtained from the PET-HMDA reaction

Chromatogram of part B-BAHT (Fig. 8A) shows a major fraction at $5.3 \mathrm{~min}$ and three minor fractions at 14.1, 14.4 and $19.5 \mathrm{~min}$, corresponding to trimer BAHT, pentamer and heptamer of AOHT, respectively as confirmed by mass spectra. The mass spectrum of the HPLC fraction at 14.4 min (peak 3, Fig. 8A) shows identical peaks as the one at $14.1 \mathrm{~min}$ (peak 2, Fig 8A) of pentamer.

Chromatogram of part A-AOHT (Fig. 8B) shows a principal peak at RT of $14.1 \mathrm{~min}$ and a minor peak at $20.2 \mathrm{~min}$, corresponding to pentamer and heptamer of AOHT, respectively as identified by mass spectra. The relative abundance of fractions in the HPLC chromatogram (Fig. 8B) shows that part AAOHT contains mainly pentamer M5 (89.2\%) and a smaller quantity of heptamer M7 (10.8\%) of OAHT. These values are quite closed to the molar percentages of M5:M7 (86.5\%: $13: 5 \%$ ) in part A-AOHT determined by ${ }^{1} \mathrm{H}-\mathrm{NMR}$.

\section{Trang 110}




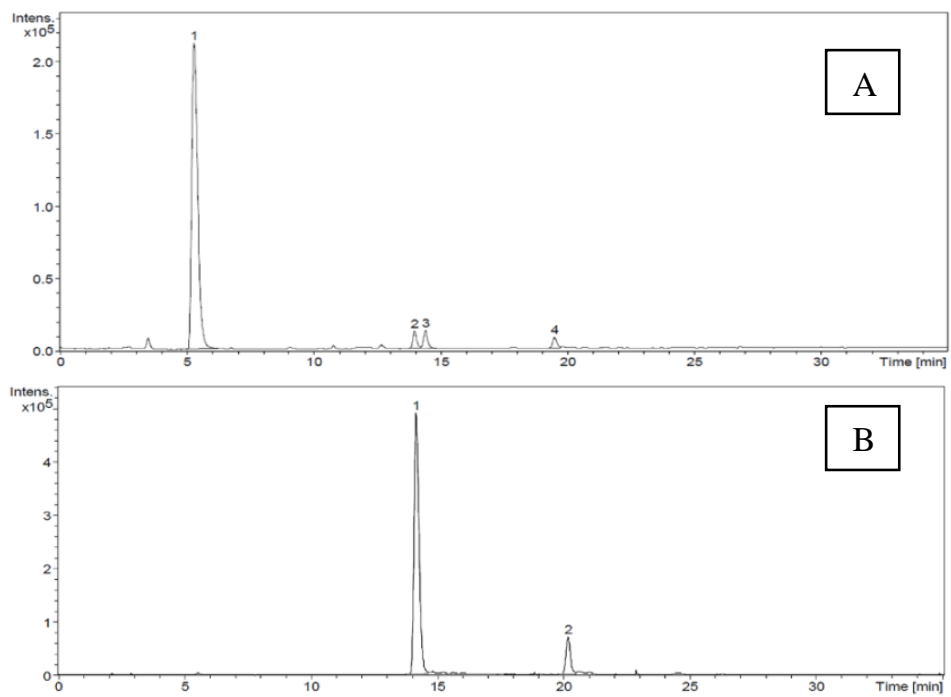

Fig. 8. HPLC chromatograms of (A) part B-BAHT and (B) part A-AOHT obtained from the PET-HMDA reaction

Optimization of reaction conditions for aminolysis of PET

Following the chemical equation in Scheme 1 , in order to obtain a trimer with $\mathrm{p}=1$, the minimum theoretical input molar ratio must be reactant diamine : PET $(2: 1)$. However, if this ratio is used and without using solvent, the quantity of diamine is too little to cover all PET flake, that requires for the efficient two phase reaction of liquid/molten diamine with solid PET. In a heterogenous reaction, the reaction rate strongly relies on the mass transfer or diffusion between these phases. As a liquid material, diamine serves not only as a reactant for PET aminolysis but also as a solvent. The larger input diamine : PET ratio resulted in the more of material exposes to reactant, thereby speeding up the reaction. In addition, the larger the input molar ratio diamine : PET is, the lower the molecular weight of oligomer will be formed.

The conversion of PET into amide was checked by observing the disappearance of PET flake and by the FTIR spectrum of the isolated products. Each reaction was carried out at least three trials to obtain the average yields of trimers and pentamers.
When molar ratio TMDA : PET of 8:1 was used (3.00 g PET, $11.02 \mathrm{~g}$ TMDA) the product consisted of $82.2 \pm 1.8 \%$ of trimer BABT and $22.1 \pm 0.9 \%$ of pentamer AOBT. In case the molar ratio TMDA : PET was reduced to 6:1, after $20 \mathrm{~h}$ of reaction, PET flake still remained in the reaction mixture, then the molar ratio TMDA : PET should not be less than 8:1.

The molar ratio of HMDA : PET was started successfully from 8:1 (3.00 $\mathrm{g}$ of PET and 15.50g of HMDA) and then also reduced to $6: 1,4: 1$ and 3:1. When HMDA : PET $=3: 1$ was used, after 18 $h$ of reaction, PET flake still existed in the reaction mixture, and consequently this lowest quantity of HMDA was not sufficient for complete aminolysis of PET. The ineffective reaction of TMDA compared to HMDA at low input molar ratio of diamine : PET can be clarified by noting the fact that the volatility of TMDA (boiling point $158-160{ }^{\circ} \mathrm{C}$ ) is higher than of HMDA (boiling point of $205^{\circ} \mathrm{C}$ ), and hence the TMDA : PET ratio was reduced faster than of HMDA : PET during the reaction.

The experimental data showed that when the higher the input molar ratio HMDA : PET was used, the faster the PET flake was consumed (9 
hrs for $4: 1$, and 7 hrs for $8: 1$ ) and the faster the reaction rate was. As the molar HMDA : PET higher than 6:1 was spent, the yields of BAHT and AOHT become unchanged (Fig. 9). Therefore the optimal input molar ratio of HMDA : PET should be $6: 1$.

Catalyst sodium acetate $\left(\mathrm{CH}_{3} \mathrm{COONa} .10 \mathrm{H}_{2} \mathrm{O}\right)$ was also added to the reaction mixture (2\% of PET by weight) of TMDA or HMDA-PET reaction, however no improvement of reaction rate was shown.

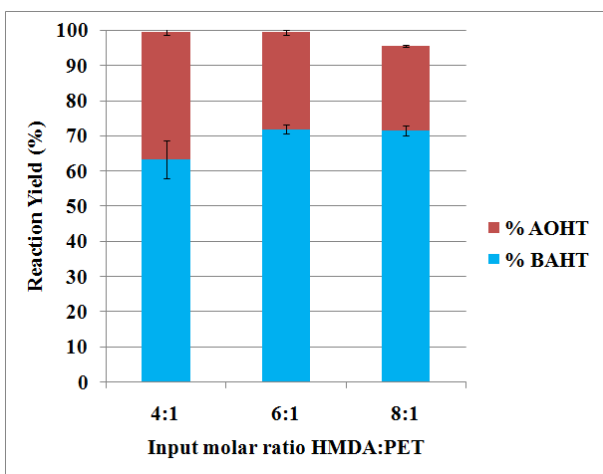

Fig. 9. Effect of HMDA:PET input molar ratios on the reaction yields of BAHT, AOHT

\section{CONCLUSION}

The aminolysis of PET waste bottle by TMDA and HMDA by a conventional heating system has been done successfully. For each used diamine, the obtained products were separated into two parts. The methanol soluble part B contains mainly a trimer and a minor quantity of pentamer, while the methanol insoluble part $\mathrm{A}$ is composed of a primary pentamer and unimportant amounts of heptamer and nonamer. The chemical tructures of the main products were confirmed by FTIR, NMR and HPLC-MS. The application of sodium acetate catalyst for aminolysis does not affect the reaction time.

These oligomer products with reactive end groups could be used as high molecular weight diamines for polyamide, polyimide, and bismaleimide preparation.

Acknowledgement: This work was supported by a grant from Vietnam National University of HCM City (project number C2014-18-06).

\section{Amine hóa vỏ chai poly(ethylen terephtalate) phế thải bằng tetra/hexamethylen diamine và phân tích các sản phẩm alpha, ohmegadiamine}

\section{- Hoàng Ngọc Cường \\ - Đặng Hoàng Yến \\ Trường Đại học Khoa học Tự nhiên, ĐHQG-HCM TÓM TĂT}

Phản úng amine hóa vỏ chai poly(ethylene terephthalate) (PET) phế thải với luợng du các diamine nhu tetramethylene diamine (TMDA) and hexamethylene diamine (HMDA) đã auợc thực hiện thành công. Mỗi trimer và pentamer trong sản phẩm được cô lập bằng cách xủ lý dung môi, tinh chế và phân tích bằng các phương pháp FTIR, NMR, và HPLC-MS. Mặc dù diamine được sủ dụng với lượng du nhưng vẫn tạo thành các sản phẩm oligomer có phân tử lượng lớn.

Tù khóa: bis(4-aminobutyl) terephtalamide (BABT); bis(6-aminohexyl) terephtalamide (BAHT); hexamethylene diamine (HMDA); oligomer; poly(ethylene terephtalate) (PET); tetramethylene diamine (TMDA); poly(hexamethylene terephtalamid); poly(tetramethylene terephtalamid); tái chế chai phế thải 


\section{REFERENCES}

[1]. G.P. Karayannidis, D.S. Achilias, Chemical Recycling of poly(ethylene terephthalate), Macromol. Mater. Eng., 292, 128-146 (2007).

[2]. L.N. Bui, M. Thompson, N.B. McKeown, A.D. Romaschin, P.G. Kalman, Surface modification of the biomedical polymer poly(ethylene terephthalate), Analyst, 118, 463-474 (1993).

[3]. A.Y. Fadeev, T.J. McCarthy, Modification of poly(ethylene terephthalate) to prepare surfaces with silica-like reactivity, Langmuir, 14, 5586-5593 (1998).

[4]. S.A. Holmes, Aminolysis of poly(ethylene terephthalate) in aqueous amine and amine vapor, J. Appl. Polym. Sci., 61, 255-260 (1996).

[5]. K.M. Haghighat, S. Borhani, Degradation cracking of poly(ethylene terephthalate) filaments by methylamine and $N$ propylamine, J. Appl. Polym. Sci., 78, 1923-1931 (2000).

[6]. L. Bech, T. Meylheuc, B. Lepoittevin, R. Roger, Chemical surface modification of poly(ethylene terephthalate) fibers by aminolysis and grafting of carbohydrates, $J$. Polym. Sci. Part A Polym. Chem., 45, 2172 2183 (2007).

[7]. Y. Avny, L. Rebenfeld, Chemical modification of polyester fiber surfaces by amination reactions with multifunctional amines, J. Appl. Polym. Sci., 32, 4009-4025 (1986).

[8]. S.R. Shukla, A.M. Harad, Aminolysis of polyethylene terephthalate waste, Polym. Degrad. Stab., 91, 1850-1854 (2006).

[9]. N.D. Pingale, S.R. Shukla, Microwave- assisted aminolytic depolymerization of PET waste, Eur. Polym. J., 45, 2695-2700 (2009).

[10]. D.S. Achilias, G.P. Tsintzou, A.K. Nikolaidis, D.N. Bikiaris, G.P. Karayannidis, Aminolytic depolymerization of poly(ethylene terephthalate) waste in a microwave reactor, Polym. Int., 60, 500506 (2011).

[11]. K. Fukushima, J.M. Lecuyer, D.S. Wei, H.W. Horn, G.O. Jones, H.A. Al-Megren, A.M. Alabdulrahman, F.D. Alsewailem, M.A. McNeil, J.E. Rice, J.L. Hedrick, Advanced chemical recycling of poly(ethylene terephthalate) through organocatalytic aminolysis, Polym. Chem., 4, 1610-1616 (2013).

[12]. R.J. Gaymans, S. Aalto, F.H.J. Maurer, Copolyamides of nylon-4,6 and nylon-4,T, J. Polym. Sci., Part A: Polym. Chem., 27, 423-430 (1989).

[13]. J. Krijgsman, D. Husken, R.J. Gaymans, Synthesis and characterisation of uniform bisester tetra-amide segments, Polymer, 44, 7043-7053 (2003).

[14]. M. Vander Schuur, B. Noordover, R.J. Gaymans, Polyurethane elastomers with amide chain extenders of uniform length, Polymer, 47, 1091-1100 (2006).

[15]. M.E. Rogers, T.E. Long, Synthetic Methods in Step-Growth Polymers, John Wiley \& Sons, Hoboken (2003).

[16]. N.C. Hoang, H.Y. Dang, Aminolysis of poly(ethylene terephthalate) waste with ethylenediamine and characterization of

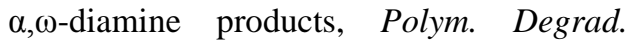
Stab., 98, 697-708 (2013). 